EGU2020-2403

https://doi.org/10.5194/egusphere-egu2020-2403

EGU General Assembly 2020

(c) Author(s) 2020. This work is distributed under

the Creative Commons Attribution 4.0 License.

\title{
Identifying buildings at risk and pedestrian travel times to safety areas in a debris flow worst-case scenario
}

\author{
Raquel Melo ${ }^{1}$, José Luís Zêzere ${ }^{1}$, Sérgio Oliveira ${ }^{1}$, Ricardo Garcia ${ }^{1}$, Sandra Oliveira ${ }^{1}$, Susana \\ Pereira ${ }^{1}$, Aldina Piedade ${ }^{1}$, Pedro Santos ${ }^{1}$, and Theo van Asch ${ }^{2,3}$ \\ ${ }^{1}$ Centre for Geographical Studies, Institute of Geography and Spatial Planning, Universidade de Lisboa, Edifício IGOT, Rua \\ Branca Edmée Marques, 1600-276 Lisbon, Portugal \\ ${ }^{2}$ Faculty of Geosciences, Utrecht University Princeton 8a, 3584 CB Utrecht, The Netherlands \\ ${ }^{3}$ State Key Laboratory of Geohazard Prevention and Geoenvironment Protection, Chengdu University of Technology, \\ Chengdu 610059, Sichuan, China
}

During the last two centuries, several debris flow events occurred in the upper part of the Zêzere valley, which is located in the Estrela mountain, in Central Portugal. These events were responsible for material damage as well as for the loss of lives. Given the susceptibility of this area to the occurrence of debris flows, a methodology for pedestrian evacuation modelling was implemented, in order to identify buildings at risk and pedestrian travel times to safety areas in a debris flow worst-case scenario. Starting from a dynamic run-out model, developed in previous works, the potential debris flow intensity was estimated (e.g. flow depth, velocity and run-out distance). Sequentially, the buildings potentially affected by the impact of debris flows, as well as the ones where the evacuation would take longer than the debris flows arrival, were identified. In addition, the potentially exposed population was estimated by applying a dasymetric distribution to each residential building. This population distribution took into account the identification of the older residents as the most exposed to debris flows, which is critical to develop reliable pedestrian evacuation travel time scenarios. The pedestrian evacuation modelling was performed using the Pedestrian Evacuation Analyst, a GIS tool developed by the United States Geological Survey. The evacuation modelling was based on an anisotropic approach, which considers the influence of slope direction on travel costs, thus its application is suitable in a mountainous area. The implemented methodology is a critical step towards the implementation of a reliable early warning system to debris flows that can be reproduced elsewhere.

Funding information: This work was financed by national funds through FCT-Portuguese Foundation for Science and Technology, I.P., under the framework of the project BeSafeSlide-Landslide Early Warning soft technology prototype to improve community resilience and adaptation to environmental change (PTDC/GES-AMB/30052/2017) and by the Research Unit UIDB/00295/2020. Pedro Pinto Santos is funded by FCT through the project with the reference CEEIND/00268/2017. 